\title{
Cândido Lusitano e o Neoclassicismo português: as considerações preliminares à tradução da Arte Poética de Horácio
}

\author{
Cláudia Teixeira \\ Universidade de Évora \\ Centro de Estudos Clássicos e Humanísticos da Univer- \\ sidade de Coimbra
}

https://dx.doi.org/10.12795/futhark.2013.i08.16

\begin{abstract}
This paper aims to analyze the "Discurso Preliminar do Traductor" which precedes the translation of Horace's Ars Poetica, published by Cândido Lusitano in 1758. In it, Cândido Lusitano reflects on the qualities of the Horatian' work, on the qualities and defects of many Commentaries and translations, published by several European commentators and translators, and on the principles that should be followed by the translators. The analysis made by Cândido Lusitano echoes the principles of neoclassical aesthetic, and thus it is intended to analyze this text in order to determine how those principles were received and understood by one of the most important theorists of Portuguese neoclassicism.

Keywords: Cândido Lusitano, translation, Neoclassicism, Ars Poetica, Horace.

Resumo: Este texto pretende analisar o "Discurso Preliminar do Traductor", que antecede a tradução da Arte Poética de Horácio, elaborada por Cândido Lusitano e publicada em 1758. Nele, Cândido Lusitano reflecte sobre as qualidades da obra horaciana, sobre as qualidades e defeitos dos comentários e traduções da Epístola aos Pisões, publicados por vários comentadores europeus e sobre os princípios tradutológicos que deveriam ser seguidos pelos tradutores. A sua reflexão insere-se na corrente neoclássica e, deste modo, pretende-se analisar este texto, no sentido de apurar a forma como foram entendidos os princípios normativos da estética neoclássica relativamente à tradução.
\end{abstract}


Palavras-chave: Cândido Lusitano, tradução, neoclassicismo, Arte Poética, Horácio.

Cândido Lusitano (1719-1773), nome arcádico do oratoriano Francisco José Freire, foi um dos mentores da implementação do neoclassicismo em Portugal. Membro da Arcádia Lusitana, academia fundada em 1757, sob o lema Inutilia truncat, por António Diniz da Cruz e Silva, Manuel Nicolau Negrão e Teotónio Gomes de Carvalho, Cândido Lusitano viria a notabilizar-se como um dos mais prolíferos teóricos da estética neoclássica, tendo, neste âmbito, dando ao prelo um Diccionario Poetico ${ }^{1}$, uma Arte Poetica ${ }^{2}$, Maximas sobre a Arte oratoria ${ }^{3}$, e ainda Reflexões sobre a Língua Portuguesa. Não menos importante foi a sua actividade tradutológica, apesar de a maioria das suas traduções não ter ultrapassado a condição do manuscrito, pois, com excepção da tradução da Arte Poética de Horácio, publicada em 1758, as versões para língua portuguesa de Sátiras e Epístolas de Horácio, dos Tristiae das Metamorfoses de Ovídio,de Hécuba, Fenícias, Hercules Furens, Ifigénia em Áulide, Ifigénia entre os Tauros e Medeia de Eurípides, do Rei Édipo de Sófocles, de Édipo e Medeia de Séneca e da Eneida de Virgílio, nunca chegaram a ser editadas ${ }^{4}$.

De um ponto de vista teórico, a obra crítica de Cândido Lusitano revela-se consonante com aquelas que, na verdade, foram as linhas de acção do neoclassicismo. Séculos depois da experiência adâmica que os primeiros cultores do humanismo mantiveram com os textos grecolatinos, a relação com os autores e textos oriundos da Antiguidade Clássica passava agora, de forma intensiva e em estreita acomodação ao espírito do lluminismo e ao combate dos excessos do barroco, pela busca de uma síntese paradigmática, resultante da conciliação entre as normas colhidas nos textos clássicos e as orientações resultantes do debate teórico que, desde meados século XVI, começara a estruturar o entendimento das poéticas clássicas em um conjunto de regras e de preceitos normativos. Por isso, não é de estranhar que a doutrinação

1 Destacam-se, neste âmbito, o Diccionario Poetico, para o uso dos que principião a exercitarse na poesia portugueza: obra igualmente util ao orador principiante,

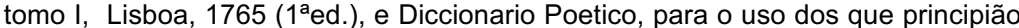
a exercitarse na poesia portugueza: obra igualmente util ao orador principiante, tomo II, 1765 ( $1^{\text {a }}$ ed. $)$.

2 Arte Poetica, ou regras da verdadeira poesia em geral e de todas as suas especies principaes, Lisboa, 1748 (segunda edição: 1759).

3 Maximas sobre a Arte oratoria, extraidas das doutrinas dos antigos mestres e ilustradas por Cândido Lusitano, Lisboa, 1759 (segunda edição dos tomos I e II: 1794; $3^{\mathrm{a}}$ ed.: 1820).

4 Além das traduções de autores gregos e latinos, Cândido Lusitano traduziu ainda, entre outros, a Athalaia de Racine e O Parto da Virgem de Sannazzaro.

Futhark 8 (2013)

Teixeira, Cândido Lusitano, 279-296

ISSN 1886-9300 
poética de Cândido Lusitano, que se tornará símbolo paradigmático deste período, assente em uma triangulação adstrita a este condicionamento, que concilia os "clássicos antigos (Longino, Aristóteles, Horácio, Quintiliano); o humanismo quinhentista, compreendendo não só os autores portugueses, mas também Castelvetro, Rubestello, Vóssio, Escalígero; os autores seus contemporâneos: Boileau, Marmontel, Voltaire, Muratori, Luzán, Addison e Pope"5.

De um ponto de vista programático, estava pois em causa a definição de simetrias reguladas com base na referida triangulação, que se pretendiam simultaneamente anuladoras quer das tensões interpretativas geradas no âmbito das sucessivas críticas e comentários às poéticas clássicas, quer reguladoras das práticas poéticas que, no âmbito do barroco, pulverizaram as regras emanadas desses textos, criando uma dispersão sem precedentes e que, segundo os neoclássicos, pouco ou nada mais representava do que a imagem da decadência das artes e da degradação das letras nacionais. Neste sentido, o corpus doutrinário neoclássico, fundado sobre a necessidade do ajustamento da Antiguidade e dos seus modelos às sensibilidades estético-morais do presente, acabaria por se constituir como um sistema de oposições relativamente à estética precedente, tanto de natureza linguística, como de natureza valorativa. Dessa teorização emergiriam como conceitos-chave imitação da natureza e decorum - conceitos que acabariam por se revelar determinantes para o espartilhamento da mundividência literária neoclássica em função de um fim ético e moral e das regras da sobriedade, da harmonia, da simplicidade, da proporção e do equilíbrio entre linguagem e assunto tratado.

Constituindo os textos antigos o meio privilegiado de acesso aos géneros, às formas e aos preceitos clássicos, necessários à "revalidação crítica das letras nacionais" 6 , foi também preocupação do neoclassicismo, na esteira do que sucedia em Portugal desde o século anterior ${ }^{7}$, o dar a conhecer a um público mais alargado possível esses textos em tradução ${ }^{8} \mathrm{O}$ exercício tradutológico permitia, na verdade, não só promover o objectivo da ilustração didáctica subjacente aos princípios actuantes do lluminismo, como constituía a forma privilegiada de pôr em contacto os leitores com a natural superioridade e perfeição dos modelos

5 Rebelo, Luís de Sousa, "Neoclassicismo", in Dicionário de Literatura, $1^{\circ}$ volume, Porto, Mário Figueirinhas Editor, 1997, pág. 708.

6 Ibidem, pág. 708.

7 Vide Corrêa, Regina helena machado aquino, "Cândido lusitano e o discurso preliminar do tradutor" Terra Roxa e Outras Terras - Revista de Estudos Literários 1, 2002, págs. 16-23.

8 Por exemplo, só da Arte Poética de Horácio é possível encontrar mais de uma dezena de traduções, elaboradas durante o século XVIII. 
antigos $^{9}$. Todavia, tal como sucedia com o debate respeitante às regras poéticas que se pretendiam adoptar como norma para a criação literária, também a tradução foi alvo de um intenso escrutínio. A discussão gerada em torno da melhor forma de traduzir, i.e., das regras e dos princípios que deviam ser aplicados de forma a que do exercício de versão se obtivesse, da forma mais rigorosa possível, o sentido verdadeiro dos textos traduzidos, alicerçou-se em convicções que resultaram tanto das controvérsias relativas aos mecanismos de transposição formal e conceptual, como da análise das traduções precedentes, feitas em várias línguas modernas, como ainda da análise da adequação ou desadequação das estruturas linguísticas vernáculas para exprimir a diversidade de formas e de sentidos oferecidos pela natural concisão e propriedade das línguas antigas. Neste sentido, compreende-se facilmente que Cândido Lusitano tenha incluído, no longo do Discurso preliminar do traductor que antecede a tradução da Arte Poética horaciana, a par das considerações sobre as qualidades do texto horaciano e da fortuna dos seus comentadores, uma longa reflexão sobre as dificuldades metodológicas deste exercício.

Sobre as qualidades do texto latino e do seu autor, Cândido Lusitano começa por enunciar o preceito da superioridade de Horácio sobre os demais poetas do século de Augusto. As apreciações de Petrónio, Quintiliano e, sobretudo, de De la Motte e Roussseau, servem-lhe de confirmação, fazendo realçar delas os elementos de que a estética neoclássica se alimentava: variedade e delicadeza, equilíbrio e proporção, simplicidade, viveza e naturalidade de exposição, novidade de figuras e expressões, subtileza na instrução moral. Em seguida, passa ao exa$\mathrm{me}^{10}$ da Arte Poética, que, apoiado em Dacier ${ }^{11}$, considera o melhor de entre todos os textos escritos pelo Venusino. Todavia, tal não Ihe impede reconhecer, entre os críticos, inúmeros detractores que, no seu jul-

9 Expressivas são as palavras de Cândido Lusitano, lidas na "Rubrica ao leitor", que antecede as traduções de Medeia de Eurípides e de Séneca (ms. CXIII/1-2-d. da BPE, 1760, f. 2r): "Em um tempo em que a Mocidade estudiosa tanto se inclina à lição da Poesia Trágica, e em que já allumiada escarnece dos miseráveis Drammas, que seus Pays nesciamente engrandeceraõ e applaudiraõ; parece-nos conveniente para mais a radicar no Bongosto da Tragédia, darlhe a ler na Linguagem Materna até onde chegara a perfeição do teatro Grego".

10 Cândido Lusitano, "Discurso Preliminar do Traductor", in Arte Poetica de Q. Horacio Flacco, traduzida e illustrada em portuguez por Cândido Lusitano, Lisboa, 1758, pág. 2 (numeração nossa): "Basta de elogios, que se nos offereceriaõ a milhares, se quizessemos andar mendigando pelos Crriticos mais judiciosos o que deixaraõ escrito sobre o merecimento de Horácio".

11 Ibidem, pág. 2: "Mons. Dacier, hum dos seus mais dignos Illustradores, confessa, que descobre nella humas bellezas taõ novas, huns preceitos taõ solidos, e hum juizo taõ profundo, e seguro, que a Antiguidade em todos os seus escritos naõ nos deixou em hum Tratado taõ breve hum igual thesouro."

Futhark 8 (2013)

Teixeira, Cândido Lusitano, 279-296

ISSN 1886-9300 
gamento, não passam, no entanto, de homens "mais cheyos de erudiçaõ, que de bom gosto"12. Entre estes, particulariza dois, a saber, Cláudio Verdério, cujo juízo classifica de "indigno, e cheyo de ignorancia"13, e Júlio César Escalígero. No entanto, contra o julgamento de Escalígero de que a Poética horaciana constitui "Arte sem arte"14, opõe, na esteira de Le Fevre, que a inobservância de um método e de uma ordem semelhantes aos seguidos por Aristóteles se deve aos objectivos inerentes à concepção forçosamente mais livre de uma epístola do que de um tratado. Mas, mais do que isso, merece-lhe especial reprovação a sentença escaligeriana de que a Poética de Horácio "só poderá agradar a meninos, e que nenhum outro juizo poderá tirar della proveito"15. A reprovação repousa, como não poderia deixar de ser, no julgamento que associa a utilidade da ArtePoética e dos seus preceitos tanto para a crítica poética ${ }^{16}$ como para a criação literária ${ }^{17}$. Em suma, brevidade, estilo sucinto, grandeza, propriedade dos preceitos, solidez dos juízos, atributos que Cândido Lusitano recupera da crítica de Dacier à Arte do Venusino, contrastam, em termos da sua utilidade, com a Poética de Escalígero que, a despeito de nela se encontrar uma "erudiçaõ infinita, hum bello methodo, e hum estylo nobre, conciso, e conveniente à materia, de que trata"18, não abre caminhos à elevação de espírito, nem à instrução ${ }^{19}$

Deixando de lado a crítica da Arte Poética horaciana com a remissão para os impugnadores de Escalígero (Bernardino Parténio, Vóssio e

12 Correia, Ana Clara dos Santos, Dicionário Poético de Cândido Lusitano - edição e estudo, Diss. de Mestrado apresentada à Universidade de Aveiro, 2007, pág. 10: "A (...) [Cândido Lusitano] se deve a "primeira definição canónica de "bom gosto"', que idealizava como o predomínio da lógica sobre a estética, "ou seja, o Juízo e criticando veementemente os excessos da liberdade criativa barroca".

13 Cândido Lusitano, 1758, pág. 2.

14 Ibidem, pág. 3.

15 Ibidem, pág. 3.

16 Ibidem, pág. 3: "Que outra obra deste genero na Antiguidade nos mostraria elle [Escalígero] mais proveitosa para a critica verdadeira sobre a Poesia?"

17 Ibidem, págs. 3-4: "Tanto he exacto, e copioso em suas regras, revestidas de ar poetico, que ainda hoje da observancia dellas depende inteirmamente a bondade, e merecimento de qualquer poema. Quem praticar sabiamente todos os seus preceitos, tenha por certo, que há de ser Poeta, se tambem a natureza lhe for benigna."

18 Ibidem, 1758, pág. 4.

19 Ibidem, pág. 4, afirma, a respeito da Poética de Escalígero: "Com tudo no solido, e fundamental falta; porque tudo funda sobre o máo gosto, e sobre humas certas miudezas, que mais pertencem ao Grammatico, do que ao Poeta. Quasi nenhum preceito dá para a grande Poesia, nenhum caminho abre ao ignorante, e nenhum socorro ministra a hum engenho, que se quer instruir. Nelle naõ se acha cousa, que eleve o espirito, e que o disponha ao enthusiasmo". 
Dacier), Cândido Lusitano anuncia que se vai centrar no motivo que levou o Venusino à composição da obra:

"O Imperador Augusto, Principe taõ benemerito das boas Artes, para que estas florecessem mais no seu Imperio, introduzio tambem em Roma o mesmo costume, fundando huma como Academia, composta de homens insignes, e para fazerem as suas conferencias, Ihes deu o Templo, e Bibliotheca de ApoIlo, que tinha dentro do seu Paço. O fim deste grande Principe na fundaçaõ desta Assemblea, foy formar hum tribunal Critico, no qual especialmente se sentenciassem as obras poeticas, para deste modo excitar os bons engenhos a se fazerem dignos de huma honrosa sentença, e reprimir os máos com o medo da censura"20.

Entre os juízes ou académicos, apontados por Teodoro Marsílio, encontravam-se Virgílio, Vário, Tarpa, Mecenas, Válgio, Octávio, os irmãos Viscos, Polião, os dois Messalas, os Bíbulos, Sérvio, Fúrnio, Tibulo, Pisão e Horácio (a estes, acrescenta Cândido Lusitano, Dacier adiciona ainda Plócio e Fusco), ou seja, figuras representativas dos círculos de Mecenas e de Messala, cujos interesses literários convergiram, de forma mais ou menos explícita, com a política cultural da Pax romana. No tocante a esta informação, apesar de pôr em dúvida o catálogo, uma vez que o final da Sátira décima do primeiro livro ${ }^{21}$, no qual Marsílio provavelmente se fundamentara para o enunciar, fora alvo de interpretações diversas, Cândido Lusitano não aplica a mesma sentença à notícia da fundação da Academia. Pelo contrário, sustentando a ideia de que "He cousa constante, que na Grecia, na Macedonia, e no Egypto desde tempo immemorial houve sempre Assembleas de gente escolhida para examinar as obras de Poesia, e de Eloquencia"22, constatação muito provavelmente apoiada na dedução historicista de que uma criação literária semelhante à produzida pelas civilizações clássicas não poderia ter existido a não ser como resultado contextual de uma actividade simultânea que a regulasse criticamente, acaba por justapor à Academia augustana um formalismo equivalente ao observado nas Academias modernas. Esta justaposição vai continuar no segmento seguinte. A despeito de reconhecer o carácter semi-conjectural ${ }^{23}$ subjacente à ideia de Marsílio de que fora "por conta do Instituto desta Assemblea" que Horácio tomara ocasião para escrever a sua Arte Poética,

Ibidem, pág. 5.

HORÁCIO, Sátiras, 1.10. 81-90.

Cândido Lusitano, 1758 , pág. 5 .

23 Ibidem, págs. 5-6, Apesar de explicitamente dizer, depois da referência ao catálogo, Marsílio "naõ pára aqui com as suas conjecturas. Pretende, que por conta do Instituto desta Assemblea, tomara Horacio a occasiaõ de escrever esta sua Arte Poetica (...)", acrescenta logo em seguida: "Se isto assim foy, que nobre exemplo para estimular aquelles Academicos da nossa idade, que passaõ a vida sem instruir o publico nas cousas, que pertencem ao seu Instituto, e à sua obrigaçaõ".

Futhark 8 (2013)

Teixeira, Cândido Lusitano, 279-296

ISSN 1886-9300 
com o objectivo de mostrar "aos poucos instruidos, o em que consistem as riquezas da Eloquencia poetica, e naõ menos os seus vicios"24, Cândido Lusitano aproveita a referência para dissertar sobre o papel das Academias e dos académicos do seu tempo, oferecendo à posteridade um reflexão crítica, que, indexada ao tempo da publicação desta tradução, deixa transparecer o sentimento de mal-estar sentido entre os intelectuais neoclássicos relativamente às actividades e orientações das instituições académicas portuguesas. Enuncia, neste sentido, a censura à falta de rigor crítico, pois, a despeito de em cada Academia existir um "mestre para dar preceitos de Oratoria, e outro para os da Poetica"25, não existe produção instrutiva que ensine, de forma sólida e em conformidade com as doutrinas clássicas, em que consistem as riquezas nem da eloquência, nem da poesia, bem como o que nutre os oradores. Por outro lado, estas palavras não deixam de sintomatizar um dos aspectos que norteava a actuação da Arcádia Lusitana, sociedade que, apesar de erigida na tradição das academias, viria a desenvolver, contrariamente à prática dominante, uma actividade crítica pró-activa, com o objectivo de promover o aperfeiçoamento poético e literário das produções a si submetidas pelos sócios: "Esta preocupação crítica (...) constituirá um dos aspectos mais importantes da sua acção. Os poetas que a integravam não tinham, como acontecia nas anteriores academias, apenas a obrigação de levarem às sessões, para aí serem recitadas e normalmente aplaudidas, as obras que compunham. Longe disso, qualquer produção poética, depois de lida, era obrigatoriamente objecto da crítica da academia, só podendo ser tornada pública como trabalho académico, depois de o autor ter aceitado as correcções a que os confrades, numa espécie de tribunal do gosto, as tivesse submetido ${ }^{26 "}$.

Do desabafo seguinte ${ }^{27}$ emerge o reconhecimento dos poetas de Quinhentos, sistematicamente depreciados no quadro das academias existentes e cuja responsabilidade na degradação da literatura Cândido Lusitano não deixa de enunciar, em uma expressiva alusão à continuidade e persistência da prática barroca no seio da criação literária portuguesa:

Ibidem, pág. 6

Ibidem, pág. 6

26 CoRreIA, J.; CÉSAR, G. "Arcádia Lusitana", in Biblos. Enciclopédia Verbo das Literaturas de Língua Portuguesa, volume $1^{\circ}$, Lisboa, Verbo, 1995, pág. 369.

27 CÂNDIDO LUSITANO, 1758, pág. 6: "Em fim, onde temos quem nos instrua no diverso merecimento dos Escritores antigos, de que foy taõ abundante Grecia, e Roma, e naõ menos dos nossos, que no seculo de quinhentos ennobreceraõ a sua lingua na prosa, e no verso? O peyor he, que estes hoje na opiniaõ de muitos passaõ por huns engenhos incultos, e os que lhes fazem mais honra, confessaõ, que seriaõ excellentes, se vivessem em nossos dias." 
"Perdoese-me esta digressaõ, que ma inspirou o zelo de desejar que as nossas Academias floreçaõ como muitas das estranhas, dando frutos maduros, com que outros Engenhos se alimentem, e naõ parando em flores de huma, ou outra composiçaõ poetica, das quais uma grande parte ainda cheira àquelle almiscar de Hespanha, que deita a perder a cabeça" ${ }^{28}$.

Em seguida, Cândido Lusitano detém-se no comentadores da Arte Poética, lançando de imediato a objecção de que ao seu elevado número não corresponde igual merecimento ${ }^{29}$, como se comprova do facto de Horácio ter sido, não poucas vezes, mal entendido. A crítica à Crítica entende-se no quadro do rigorismo que marcou as polémicas relativas à interpretação do textos, decorrentes da "preocupação de sistematizar o fenómenos literário" ${ }^{30}$. Na verdade, se essa sistematização foi, por um lado, marcada pela "necessidade de estabelecer um conjunto orgânico de regras que pudesse disciplinar a actividade literária, desde os aspectos mais simples até às formas mais complexas do significado." ${ }^{31}$, por outro lado, o corte longitudinal realizado pelos teóricos sobre os textos clássicos, no sentido de deles se apurar o conjunto dessas regras e princípios, acabaria rapidamente complementado, ou até superado, por acareações transversais entre comentadores e comentários e que expressam bem não só a árvore genealógica das filiações críticas, como as divisões existentes no quadro da emergente instituição literária europeia. Curiosa não deixa de ser a observação que Cândido Lusitano faz em seguida a um dos elementos que, no âmbito dessa instituição, se viria a consagrar como factor da validação institucional da literatura e da constituição dos cânones, quer literários, quer críticos: a autoridade patrocinada "por hum grande numero de Authores". Na verdade, e apesar de Horácio ter sido frequentemente desfigurado (opinião que fundamenta em Dacier), isso não impede que "a maior parte da gente" tivesse seguido as conclusões expostas nesses comentários ${ }^{32}$, formando, muitas vezes, cadeias de erro interpretativo. Deixando de lado a queixa contra o capital simbólico de alguns críticos que, apesar de tudo, não nomeia explicitamente, Cândido Lusitano vai proceder à análise dos méritos dos comentadores por si lidos e estudados. Da Antiguidade, apenas Acron e Porfírio Ihe merecem referência para deles dizer que

28 Ibidem, pág. 6

29 Ibidem, pág. 7: "Passando a dar ao leitor alguma noticia dos Commentadores, que tem illustrado esta Arte, devemos confessar, que saõ muitos em numero, e poucos em merecimento"

30 Aguiar e Silva, V., Teoria da Literatura, Livraria Almedina, Coimbra, 1992, $8^{a}$ ed., pág. 508.

31 Ibidem, pág.509.

32 CÂNDIDO LUSITANO, 1758, pág. 7: "Importa pouco, que esta [a força da razão] dicte huma cousa; basta, e sobra para logo a crerem, que a diga hum Escritor, e que a confirmem muitos."

Futhark 8 (2013)

Teixeira, Cândido Lusitano, 279-296

ISSN 1886-9300 
ilustraram Horácio mais no "sentido grammatical, mythologico, e histórico, do que no poetico. Se outros depois naõ tomassem a mesma empreza, naõ perceberiamos os solidos, e occultos preceitos, que dá aos Poetas na sua admiravel Arte." ${ }^{\text {"33 }}$ Não resta margem para dúvida de qual é o âmbito de interesse relativamente a Horácio. A autonomização do "poético", que se divisa do corte metodológico operado em relação aos outros campos de análise, deixa bem clara a preocupação a que se vai subordinar a própria análise de Cândido Lusitano, extensamente disseminada por notas explicativas e ainda por um "Suplemento às notas" e uma rubrica, intitulada "Observações do tradutor". A lista de comentadores analisados é extensa: P. Nânio (P. Nanninck), P. W. Chabot, D. Lambino, G. Xilandre, Messénio (Jacques de Crucque), F. Luisino, J. de Nores, G. Grifoli, C. Landino, H. Glareano, T. Marsílio, Aquiles Estaço, Tomé Correia, A. Dacier, R. Bentley, o jesuíta Juvency, Du Hamel, L. Despreaux e o Brocense. Embora seja demorado explanar caso a caso, penso que valerá a pena, contudo, dizer que do conjunto só Dacier ${ }^{34}$, Estaço e o Brocense Ihe merecem apenas elogios. Juvency e Du Hamel escapam igualmente a qualquer censura, mas o facto de Cândido Lusitano classificar os respectivos comentários como obras destinadas a principiantes redimensiona necessariamente o campo do elogio. Dos outros são escrutinados tanto os vícios como as virtudes, dando também Cândido Lusitano frequentemente nota da apreciação geral, e muitas vezes controversa, de que cada um gozava entre os estudiosos e, em alguns casos, nota de julgamentos e polémicas particularizados e individualizados. Entre as críticas negativas sobressaem, na apreciação de Cândido Lusitano, a análise de aspectos retóricos, gramaticais, mitológicos ou históricos, em detrimento do "poético" (e.g. Chabot, Despreaux), o errado entendimento de expressões e princípios horacianos (e.g. Nânio, Grifoli; e, por vezes, Nores e Luisino), a erudição excessiva e, por vezes, inconveniente (e.g. Nânio, Chabot, Lambino, Luisino), a omissão de passos complicados e controversos (e.g. Nânio, Lambino, Grifoli, Marsílio), a falta de autores e de autoridades clássicas no aparato crítico (e.g. Landino), a excessiva brevidade (e.g. Marsílio). No tocante às virtudes, o bom entendimento das expressões e dos preceitos horacianos (e.g: de Nânio destaca, apesar do julgamento relativo ao mau entendimento de alguns passos, o ter sido o primeiro a chamar a atenção para alguns loci e para o verso Pictoribus, atque Poetis...), o

33 Ibidem, pág. 7

34 Cândido Lusitano confessa, na página 24 deste Discurso, que seguiu Dacier não só na tradução como também nas notas e explicações dos passos. Subsidiariamente, acrescentou outras informações, colhidas em outros comentadores, e corroborou os preceitos da Arte com exemplos retirados de autores clássicos e nacionais. Usou também os textos de diversos autores portugueses e estrangeiros, para demonstrar (e censurar) os desvios relativamente às regras horacianas. 
confronto entre manuscritos e a correcção de erros do texto latino (e.g. Lambino, Messénio, Marsílio, Estaço), a boa ilustração dos passos com autores antigos (e.g. Lambino, Messénio, Luisino, Estaço, Dacier), o tratamento dos passos difíceis e das dificuldades da obra (e.g. Luisino, Dacier), a explicação clara, profunda ou rigorosa dos preceitos horacianos (e.g. Dacier, Landino, o Brocense).

Por fim, diz ter notícia de outros comentários, que lamenta não conhecer, entre os quais o de Robortello e o de Bento Pereira.

Por fim, Cândido Lusitano entra naquele que será o último assunto por si debatido neste Discurso preliminar: a tradução. Depois de dar nota crítica dos defeitos e virtudes de várias traduções italianas, francesas e espanholas da Arte Poética horaciana, Cândido Lusitano vai reflectir sobre a sua própria tradução. Isso implica, como não poderia deixar de ser, reflectir sobre os princípios tradutológicos de uma actividade revalorizada na época, mas que não deixa, por isso, de ser palco de tensões metodológicas. Neste capítulo, sobressai, como elemento central da discussão, a clivagem observada entre dois modos de traduzir:

“(...) saõ nos Criticos judiciosos muy diversas as sentenças sobre as obrigações de hum Traductor. Huns querem, que seja hum fiel copiador, naõ só das expressões, mas até das mesmas palavras daquelle, a quem traduz: outros daõ mais liberdade, dizendo, que deve vestir com as galas da sua lingua aquellas expressões, elegancias, e fórmas particulares de dizer, que na lingua do texto apparecem com adorno. (...) Estes para assim se defenderem do impertinente escrupoloso dos outros, tem a suprema authoridade dos dous mayores juizos da Antiguidade, Horacio na Poetica, e Cicero ${ }^{35}$ no Tratado de Optim. Gener. Orator. (...)"36.

Estas palavras deixam inferir a tensão existente entre o que vulgarmente se sintetiza nos conceitos de "tradução de poesia" e "tradução poéti$\mathrm{ca}^{\mathrm{3} 37}$. A consciência de que traduzir, longe de implicar mera equivalência

35 CÂNDIDO LuSITANO, 1758, pág. 18, traduz as palavras de Cícero (De Optimo Genere Oratorum, 14.3-15.1), relativamente à tradução dos discursos de Demóstenes e Ésquino, em que se vai apoiar para defender o seu ponto de vista: "Traduzi-as, conservando não menos as mesmas sentenças, e differentes fórmas de dizer, que as figuras; mas expliqueime segundo o nosso costume, julgando, que não era preciso traduzir palavra por palavra, bastando conservar a força, e propriedade dos termos; porque entendi, que isto de traduzir, naõ he dar ao leitor as coisas por conta, mas por pezo."

36 Ibidem, pág. 18.

37 Balbuena Torezano, M. C., "Traducir a Friedrich Schiller: a propósito de Die Götter Griechenland, Futhark 5, 2010, págs. 80-81: "La traducción poética exige del traductor la elaboración de outro poema equivalente al original - de ahí que muchos especialistas afirmen que la traducción poética es imposible -; por el contrario, la traducción de poesía es una traducción funcional, y según Martínez Merlo posibilita al lector del TM '[...] el rastreo del original, permitiéndole conocer en éste com claridad aquello que facilmente va siguiendo en su lengua'. Dicho de outro modo:

Futhark 8 (2013)

Teixeira, Cândido Lusitano, 279-296

ISSN 1886-9300 
lexical, envolve um processo de comunicação cultural e linguística, que leve a uma efectiva "transposição de sentido" ${ }^{38}$, constituía já um processo reconhecido desde a Antiguidade e esteve presente também na reflexão dos primeiros teorizadores ${ }^{39}$. No Renascimento, apesar de se registar uma continuidade relativa ao facto de os princípios da tradução resultarem mais de um certo empirismo e de uma reflexão descontinua$\mathrm{da}^{40}$ cujos "(..) statements and theories (...) stem directly from the practical work of translating." ${ }^{41}$, essa consciência tornar-se-ia cada vez mais expressiva entre os tradutores. Tal não obstou, todavia, a que as duas sensibilidades sobre o modo de traduzir, que o texto supracitado de Cícero deixa subentender, se mantivessem activas e em debate. $E$, neste capítulo, Cândido Lusitano não oferece margem a qualquer hesitação, colocando-se do lado daqueles que dão primazia a uma tradução que ofereça ao leitor "sentido-por-sentido"42 e não "palavra-por-palavra". Esta opção desenvolvia-se também já na esteira de uma longa tradição, a partir de princípios que Cândido Lusitano define, ainda com base no texto ciceroniano, da seguinte forma:

la traducción poética exige una sensibilidad propria de un poeta, de forma que el traductor ha de experimentar todos aquellos sentimientos y situaciones del mismo modo que lo hizo el autor del TO, para, tomando como fuente dicho texto, crear, como si de un espejo se tratara, un nuevo poema que sea el fiel reflejo del traducido. Es, por tanto, el medio para trasvasar la poesía de una cultura a outra, manteniendo todas y cada una de sus características literarias y no literárias".

38 Das, Bijay Kumar, Handbook of translation studies, New Delhi, Atlantic, 2009, págs. 37-38: "A translator, in the first place, should possess an inwardness with both de languages - the source language (SL), from which the translation is to be made, and the target language (TL) into which the translation is to be done. He should have a mastery over both languages and the words should "obey his call". Above all, he should have the "fell" of the language. Secondly, in case of literature translation, literal translation should be avoided at all costs because it fails de transposition of culture. The translator should not only give the lexical equivalent of words but keep in mind the socio-cultural matrix. Language is never a mcehanical sound sistem, for each word is charged with memory, associations and literary allusions." No mesmo sentido, BASSENETT, Susan, Translation Studies, London, Routledge, 1988, pág. 21: "Beyond the notion stressed by the narrowly linguistic approach, thar translation envolves the tranfer of 'meaning' contained in one set of language signs into another set of language signs through competent use of the diccionary and grammar, the process envolves a whole set of extra-linguistic criteria also."

39 Vide Bassenett, 1998, págs. 58-59.

40 Munday, Jeremy, Introducing Translation Studies: Theories and Application, London, Routledge, 2001, págs. 24-25: "Theory was generally unconnected; it amounted to an albeit broad series of prefaces and comments by practitioners who often ignored, or were ignorant of, most of what had been written before."

41 Bassenett, 1998, pág.46, comentando Steiner (After Babel).

42 Munday, 2001, pág. 19. 
Desta authoridade claramente se colhe, que a Traducçaõ para ser boa, he preciso, que conserve com a fidelidade possivel todo o caracter, e indole do texto; (...) Nos por fidelidade (...) entendemos (...) o exprimir (quanto for possivel) sentença por sentença, e figura por figura, naõ accrescentando cousa que naõ se lêa no original, e naõ menos tirando, ou mudando cousas que nelle estejaõ". (...) O caracter, ou indole consiste em saber conservar na Traducçaõ a mesma gala, o mesmo ar, nobreza, e affectos, com que se exprime o texto, a cuja circunstancia propriamente chamavaõ os Antigos Cores" ${ }^{\prime 3}$.

Reconhecendo "ciência e eloquência" como os requisitos básicos para alcançar respectivamente os propósitos da fidelidade e da índole, observa, em seguida, que ambos são difíceis de atingir e muito mais o são, quando buscados em simultâneo. Servem-lhe de exemplo a tradução de Xenofonte, realizada por Filelfo, a de Platão, feita por M. Ficcino. Em ambas se regista a tradução de todas as palavras do texto de origem, mas à primeira falta-lhe fidelidade e carácter e à segunda a índole, isto é, "aquella magestade, e elegancia de Plataõ"44. Já Lapo Florentino soubera desenhar a índole, mas falhara na transposição do estilo. Não obstante as dificuldades de juntar no mesmo tradutor as duas qualidades, prossegue, houve alguns especialmente felizes: além dos enumerados por Baillet, distinguem-se, entre outros, Erasmo, Budé, Poliziano, Hermolau Bárbaro, Rodolfo Agrícola, que "satisfizeraõ felicissimamente às obrigações de Traductores, exprimindo com grande cuidado naõ só a força das palavras, mas a dos pensamentos, e a do caracter especifico daquelles, a quem traduziraõ. Distingue-se entre todos Policiano; porque

43 CÂNDIDO LUSITANO, 1758, pág. 18. Munday, 2001, pág. 25, observa a ambivalência destes conceitos: "Kelly looks in detail at the history of western translation theory, starting with the teachings of the writers of Antiquity and tracing the history of what he calls ( $p .215)$ the 'enextricably tangled' terms 'fidelity', 'spirit', and 'truth'. The concept of fidelity (or, at least the translator who was fidus interpres, i.e., the 'faithful interpreter') had initially been dismissed as literal word-for-word translation by Horace. Indeed, it was not until the end of the seventeenth century thar fidelity really came to be identified with faithfulness to the meaning rather than the words of the author. Kelly (1979: 206) describes spirit as similarly having two meanings: the latin word spiritus denotes creative energy or inspiration, proper to literature, but St Augustine used it to mean the Holy Spirit, and his contemporary St Jerome employed it in both senses. For St Agustine spirit and truth (veritas) were intertwined, with truth having the sense of 'content'; for St Jerome, truth meant the authentic Hebrew text to which he returned in is Vulgate translation. Kelly considers that it was not until the twelfth century that truth was fully equated with 'content'. (...) However, by the seventeenth century, fidelity had come to be generally regarded as more than just fidelity to words, and spirit lost the religious sense it originally possessed and was thenceforth used solely in the sense of creative energy of a text or language."

44 Cândido Lusitano, 1758, pág. 19.

Futhark 8 (2013)

Teixeira, Cândido Lusitano, 279-296

ISSN 1886-9300 
vivissimamente representa em tudo a figura, e indole do Escritor, que traduz."45.

Em seguida, sobre a sua própria tradução, diz Cândido Lusitano que Ihe parece ter exprimido "à portuguesa" todo o sentido de Horácio e também o seu estilo, com excepção da brevidade, impossível de conseguir em verso, como, aliás, bem o atestam algumas traduções francesas e italianas. Contudo, não aprova traduzir em prosa, pelas razões que invoca a propósito da tradução de Marolles. A verdade é que não aponta nenhuma, limitando-se a transcrever o passo de Parnasse Réformé (Gabriel Gueret, 1669), no qual o próprio Horácio "se queixa" do estropiamento de que é alvo, em virtude da manifesta incapacidade dos tradutores de o manterem em verso:

"Voilá les beaux exploits de cette nouvelle secte de Traducteurs ; ne pouvant s'élever jufques à nous, ils nous abaissent jusques à eux, et nous font ramper comme des miserables ; parce qu'il leur eft impossible de suivre noftre rapidité qui les entraine, ils nous estropient; et par un défaut de jugement, ou de veine poétique, ils mettent tout en prose jusqu' à nos chansons"46.

Desta forma, afirma Cândido Lusitano ter optado pelo verso, não por qualquer um, mas por aquele que se revela mais adequado aos seus propósitos de "expor com liberdade, e clareza os pensamentos, e carácter de Horacio"47, ou seja, o verso solto. Todavia, consciente de que a opção não agradaria a todos, propõe-se explicar e fundamentar as razões pelas quais a rima é perniciosa à liberdade da poesia, sendo que o é especialmente no caso das traduções. A defesa da abolição da rima, defendida pela estética neoclássica porquanto mecanismo de constrição do pensamento e da liberdade poética, vai passar por um conjunto de argumentos de natureza linguística e valorativa: assim, a consciência de que as línguas vivas constituem realidades linguisticamente inferiores ao latim e ao grego, não impediu, na verdade, que Camões tivesse sido um "Pintor" semelhante a Homero e a Virgílio; todavia não os igualou na viveza e naturalidade do colorido, precisamente porque não tinha ao seu dispor um verso semelhante ao hexâmetro. A natureza do hexâmetro, que não exige uniformidade de "terminações", não se restringe à necessidade de cadências, não admite palavras desnecessárias, não impede variações de medida, número, harmonia ${ }^{48}$, constitui vantagem que se não observa na poesia vulgar, nascida nos séculos bárbaros e escrava da rima. Por isso, com excepção do seu uso na poesia lírica e nas composições destinadas a serem musicadas, reprova-a tanto nas composições em que o poeta fala, como naquelas em que se esconde (poesia

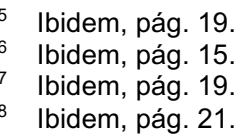


dramática). E a razão não é apenas estética: a rima transferiu o deleite causado ao entendimento e à imaginação para os ouvidos. Semelhante juízo proferira já Cândido Lusitano, ao analisar, na sua própria Arte Poética, publicada em 1748, a presença da música nas representações dramáticas $^{49}$, elemento que, tal como a rima em relação à poesia, se configura como lesiva da sensibilidade dramática grega e latina e do decorum neoclássico. Além disso, bons exemplos da prática do verso solto são oferecidos pelas nações mais cultas: a somar à boa tradição italiana, os ingleses usam-na não apenas nas composições dramáticas, mas também na épica (Milton, em Paraíso Perdido); os franceses conservam a rima, por "necessidade", i.e., por não terem uma língua que possa "conservar a gravidade poetica sem o arrimo das consoantes." entre nós, a Castro,de António Ferreira, e o Naufrágio do Sepúlveda, de Corte-Real, são exemplos do uso do verso solto, embora o segundo tivesse diminuído o seu merecimento, devido ao verso rimado que usa nas enunciações discursivas do poema. Por outro lado, o preconceito da dificuldade tem limitado o abandono da rima, pois o seu uso ainda se encontrava, na mente de muitos poetas, ligado à grandeza e graça da poesia. Assumindo, todavia, na esteira de Salvini, Maffei e Pope, que o verso solto é mais difícil do que o rimado, dita sobre eles a sentença de que, no caso do primeiro, é intrínseco o seu valor ao passo que, no segundo, a rima nada mais é do que uma maquilhagem que encobre os seus defeitos.

Em suma, se a rima constrange a liberdade poética e impede a acomodação da forma ao assunto, promovendo o sacrifício do significado e da viveza a um formalismo vazio, impede-o ainda mais no caso da tradução, "porque está ligado a pensamentos e expressões alheas." ${ }^{51}$ Neste sentido, a consciência de que a translatividade constitui um espaço no qual o tradutor tem um dever moral não só para com os leitores, mas também para com os autores e textos traduzidos, estende-se agora ao aspecto formal. Na verdade, se a opção por uma tradução de "sentido", em detrimento da tradução "palavra-por palavra", constituía a face mais valorizada de uma cultura que equacionava os textos clássicos como "an artefact of a particular cultural system"52, e cuja tradução só seria fiel se lhe pudesse dar "a similar function in the target cultural system" ${ }^{53}$, a

49 CÂndido lusitano, Arte Poética ou Regras da verdadeira Poesia em geral, e de todas as suas especies principaes, tratadas com juizo critico, $2^{\mathrm{a}}$ ed. (edição consultada), tomo II, Lisboa, 1759, cap. XVI: "Dos defeitos que se podem observar nos Dramas modernos. A sua música perniciosa aos costumes, e reprovada ainda pelos antigos".

50 CÂNDIDO LUSITANO, 1758, pág. 23.

51 IBIDEM, pág. 24.

52 BASSENETT, 1988, pág. 61.

53 BASSENETT, 1988, pág. 61.

Futhark 8 (2013)

Teixeira, Cândido Lusitano, 279-296

ISSN 1886-9300 
verdade é que esse pressuposto não deixou de passar também por questões técnicas e formais que, em última análise, contribuíram para a sua validação, como bem o expressam as palavras de Cândido Lusitano a propósito da sua opção pelo verso solto:

"Eis aqui os fundamentos, porque escolhemos o verso solto para a nossa tradução. Só com esta liberdade he que entendemos, que poderiamos rastejar em exprimir a Horácio com termos fieis, e que naõ desdissessem do seu caracter. Para mais o imitar, até fizemos muito por naõ uzarmos de versos sonoros, e nimiamente artificiosos; antes lhe demos um certo ar de proza, para assim exprimirmos no possivel o estylo, e metro do original, que he o que unicamente convem às Satyras, e Epistolas. Largamente o mostraraõ Blondel e Grocio, censurando com razaõ aquelles, que daõ bem a conhecer o seu pessimo discernimento, naõ compreendendo a especial graça, e belleza Poetica, que dá Horacio às suas Satyras, e Epistolas com huma certa estudada negligencia de metro, e com hum ar de proza no estylo. Esta especialidade do nosso Poeta he taõ difficil de entender, como de imitar. Quanto tem emprendido imitarlhe o estylo? E quantos o conseguiraõ? Por certo, que muitos seriaõ seus imitadores, se bastasse simplesmente fazer versos prosaicos; como diz o mesmo Poeta na Satyra 4 do liv. I (...)"54

Por fim, depois de se referir à metodologia adoptada para as anotações ${ }^{55}$, introduz aquilo a que poderíamos chamar um case study, não fosse o facto de, subjacente a tal caso, haver apenas uma intenção de defesa relativamente a putativos críticos, e que diz respeito aos seguintes versos da Arte Poética (46-48) horaciana:

"In verbis etiam tenuis, cautusque serendis, dixeris egregiè, notum si callida verbum reddiderit junctura novum".

Diz Cândido Lusitano que tomou a liberdade de variar a metáfora (subentende-se, contida pela correlação que se estabelece entre a expressão in uerbis ... serendis e a palavra iunctura), usando antes o sentido do verbo forjar em vez de semear, pois "a palavra junctura, ${ }^{56}$ naõ se apropria bem à methafora escolhida pelo Poeta, mas sim à que desco-

54 CÂNDIDO LUSITANO, 1758, pág. 24-25

55 Vide nota 34

56 Observa Fernandes, R. M. Rosado, Horácio, Arte Poética (introdução, tradução e notas de R. M. Rosado Fernandes), Lisboa, Editorial Inquérito,1984, pág. 56, comentário aos versos 47-48: "Callida iunctura: trata-se, segundo afirma Rostagni, da metáfora, na qual é possível, por hábil combinação, transformar o sentido de uma palavra, ao colocá-la num contexto desabitual. (...) Horácio dá, juntamente com o preceito, um exemplo que o corrobora. Efectivamente, a expressão do v. 46 , in uerbis ... serendis, está pela mais habitual, in uerbis inueniendis. A expressão horaciana provém de uma metáfora de origem agrícola e traduz-se literalmente: "no semear de vocábulos" (...)". 
brio o Traductor"57. Neste sentido, e depois de aprovada a escolha por diversos amigos, sobretudo aqueles que fazem parte da Academia Lusitana, optou pela seguinte tradução (que apresenta apenas no corpo da tradução da Arte Poética de Horácio, p. 27):

"No forjar de palavras peregrinas

Te mostrarás também discreto, e parco:

E dirás muito bem, se judicioso

Soldando duas vozes já sabidas

Subtilmente formares huma nova".

Todavia para evitar a censura de algum crítico, diz Cândido Lusitano, resolveu traduzir o passo, neste lugar, e apenas para esse mesmo crítico, tradução que apresenta com a seguinte forma:

"No semear de vozes peregrinas

Te mostrarás também discreto, e parco;

E dirás muito bem, se judicioso

Enxertando duas vozes já sabidas

Com destreza formares huma nova"58.

Não cabe, neste artigo, a análise da tradução da Arte Poética horaciana realizada por Cândido Lusitano. No entanto, o exemplo em análise é bem significativo das tensões existentes no quadro da actividade tradutológica. Descontando as dificuldades em conter a versificação nos moldes quantitativos da língua original, algo que, na consciência dos neoclássicos, resultava das próprias deficiências das línguas modernas, a alteração impressa parece bem expressiva de um dos elementos, que no século XVIII, se configuraria como próprio da actividade de traduzir, i.e,

"The right of the individual to be addressed in his own terms, on his own ground (...). The impulse to clarify and make plain the essential spirit of a text led to large-scale rewritings of earlier texts to fit them to contemporary standards of language and taste" 59 .

Este movimento levou a que um número significativo de textos traduzidos, entre os quais os de Cândido Lusitano, sejam hoje entendidos como paráfrases. Todavia, a cristalização das traduções do período neoclássico sob esta forma resultou de uma opção, cujos contornos têm de ser avaliados em relação às condicionantes do período. Assim, se por um lado, a primazia dada às "traduções de sentido", porquanto se revelavam mais fieis do que as congéneres que se limitavam a traduzir

57 Cândido Lusitano, 1758, pág. 26.

58 Ibidem, pág. 26.

${ }^{59}$ BASSENETT, 1988, pág. 65.

Futhark 8 (2013)

Teixeira, Cândido Lusitano, 279-296

ISSN 1886-9300 
palavra por palavra, ofereceram uma abertura a uma transposição mais livre, por outro lado, essas traduções viveram também de uma dialéctica epocal que visou, de forma simultânea, recuperar o passado e afirmar do presente. Em sentido mais lato, poder-se-á concluir que, neste capítulo, as considerações que Cândido Lusitano expressa neste seu Discurso Preliminar à tradução da Arte Poética de Horácio testemunham a forma como os neoclássicos entenderam a recuperação da Antiguidade e dos seus modelos cognitivos; uma recuperação em que o esforçado ajustamento ao tempo presente dos textos e modelos clássicos não se esgotou no mero objectivo de os entender intelectualmente, enquanto objectos situados no quadro em que foram produzidos, mas que pretendeu também actualizá-los de forma a que contribuíssem para a definição e regulação do mesmo presente que, simultaneamente, os recuperava.

\section{Referências bibliográficas:}

\section{1) Textos de Cândido Lusitano:}

CÂNDIDO LUSITANO, Arte Poetica de Q. Horacio Flacco, traduzida e illustrada em portuguez por Cândido Lusitano, Lisboa, 1758.

CÂNDIDO LUSITANO, Arte Poética ou Regras da verdadeira Poesia em geral, e de todas as suas especies principaes, tratadas com juizo critico, $2^{\mathrm{a}}$ ed. (edição consultada), tomo II, Lisboa, 1759.

CÂNDIDO LUSITANO, Traduções de Rei Édipo de Sófocles e Édipo de Séneca, ms. XIII/1-1-d. da BPE, 1760.

2) Estudos:

AGUIAR E SILVA, Vítor, Teoria da Literatura, Livraria Almedina, Coimbra, 1992, $8^{\text {a }}$ ed.

Balbuena ToRezano, M. C., "Traducir a Friedrich Schiller: a propósito de Die Götter Griechenland", Futhark 5, 2010, 75-94.

BASSENETT, Susan, Translation studies, London, Routledge, 1988.

CASTRO, Aníbal Pinto de, Retórica e Teorização Literária em Portugal: Do Humanismo ao Neo-Classicismo, $2^{\mathrm{a}}$ ed., Lisboa, Imprensa Nacional Casa da Moeda, 2008.

CORRÊA, Regina Helena Machado Aquino, "Cândido lusitano e o discurso preliminar do tradutor" Terra Roxa e Outras Terras - Revista de Estudos Literários 1, 2002, 6-23.

CorReIA, Ana Clara dos Santos, Dicionário Poético de Cândido Lusitano edição e estudo, Diss. de Mestrado apresentada à Universidade de Aveiro, 2007.

CORREIA, J.; CÉSAR, G., "Arcádia Lusitana", in Biblos. Enciclopédia Verbo das Literaturas de Língua Portuguesa, volume 1, Lisboa, Verbo, 1995. 
DAS, Bijay Kumar, Handbook of translation studies, New Delhi, Atlantic, 2009.

FERNANDES, R. M. Rosado, Horácio, Arte Poética (introdução, tradução e notas de R. M. Rosado Fernandes), Lisboa, Editorial Inquérito, 1984.

FERRO, Manuel Simplício, A recepção de Torquato Tasso na épica portuguesa do Barroco e Neoclassicismo, diss. de Doutoramento apresentada à Universidade de Coimbra, 2007.

LEFEVERE, A. (ed.), Translation/History/Culture: a Sourcebook, London, Routledge, 1992.

MUNDAY, Jeremy, Introducing Translation Studies: Theories and Application, London, Routledge, 2001.

Rebelo, Luís de Sousa, "Neoclassicismo", in Dicionário de Literatura, $1^{\circ}$ volume, Porto, Mário Figueirinhas Editor, 1997.

RoBINSON, Matthew, The Poetry of Translation: the art of the impossible, Liverpool University Press, 2010.

ISSN 1886-9300 